\title{
NEW EXPLICIT BOUNDS ON GAMIDOV TYPE INTEGRAL INEQUALITIES ON TIME SCALES AND APPLICATIONS
}

\author{
Khaled Boukerrioua, Dallel Diabi and Imen Meziri
}

\begin{abstract}
In this paper, we derive some generalizations of certain Gamidov type integral inequalities on time scales, which provide explicit bounds on unknown functions. Also, some examples are presented to show the feasibility of these results.
\end{abstract}

Mathematics subject classification (2010): 26D10, 26D15.

Keywords and phrases: Dynamic equations, time scale, integral inequality, mean value theorem.

\section{REFERENCES}

[1] D. Bainov AND P. Simeonov, Integral inequalities and applications, vol. 57 of Mathematics and its applications, Kluwer Academic Publishers, Dordrecht, 1992.

[2] B. Ben NASSER, K. Boukerrioua AND M. A. Hammami, On the stability of perturbed time scale systems using integral inequalities, Appl. Sci. 16 (2014) 56-71.

[3] B. Ben Nasser, K. Boukerrioua And M. A. Hammami, On stability and stabilization of perturbed time scale systems with Gronwall inequalities, Journal of Mathematical Physics, Analysis, Geometry 11 (3), 207-235.

[4] M. Bohner and A. Peterson, Dynamic Equations on Time Scales: An Introduction with Applications, Birkhäuser, Boston, Mass, USA, 2001.

[5] M. Bohner And A. Peterson, Eds., Advances in Dynamic Equations on Time Scales, Birkhäuser, Boston, Mass, USA, 2003.

[6] K. Boukerrioua And A. GueZane-Lakoud, Some nonlinear integral inequalities arising in differential equations, EJDE, vol. 2008 (2008), no. 80, pp. 1-6, http://ejde.math.txstate.

[7] K. Cheng, C. Guo, New Explicit Bounds on Gamidov Type Integral Inequalities for Functions in Two Variables and Their Applications, Abstract and Applied Analysis 2014, Article ID 539701, 9 pages.

[8] K. Cheng, C. Guo, M. TAng, Some Nonlinear Gronwall-Bellman-Gamidov Integral Inequalities and Their Weakly Singular Analogues with Applications, Abstract and Applied Analysis 2014, Article ID 562691, 9 pages.

[9] R. A. C. FERreira AND D. F. M. Torres, Generalizations of Gronwall-Bihari inequalities on time scales, Journal of Difference Equations and Applications 15 (2009), no. 6, 529-539.

[10] SH. G. Gamidov, Certain integral inequalities for boundary value problems of differential equations, Differ. Uravn. 5, 3 (1969), 463-472.

[11] F. JiAnG, F. MENG, Explicit bounds on some new nonlinear integral inequalities with delay, Journal of Computational and Applied Mathematics 205 (2007), 479-486.

[12] S. D. Kendre, S. G. LATPATE, On some mixed integral inequalities and its applications, Theoretical Mathematics Applications, vol. 5 (2013), no. 1, 1-14.

[13] B. G. PACHPATtE, Inequalities for Differential and integral equation, Academic Press, New York, 1998.

[14] B. G. PachpatTE, A note on certain integral inequality, Tamkang Journal of Mathematics, vol. 33, no. 4, pp. 353-358, 2002.

[15] B. G. PACHPATTE, Integral and finite difference inequalities and applications, North-Holland Mathematics studies, 205, 2006. 
[16] B. G. Pachpatte, Explicit bounds on Gamidov type integral inequalities, Tamkang Journal of Mathematics, vol. 37, no. 1, pp. 1-9, 2006. 